\title{
Systemic elucidation on the potential bioactive compounds and hypoglycemic mechanism of Polygonum multiflorum based on network pharmacology
}

Yunfei Song ${ }^{1,2+} \mathbb{0}$, Jianbo Yang ${ }^{2 \dagger}$, Wenguang Jing ${ }^{2}$, Qi Wang ${ }^{2}$, Yue Liu ${ }^{1}$, Xianlong Cheng ${ }^{2}$, Fei Ye ${ }^{3}$, Jinying Tian ${ }^{3}$, Feng $\mathrm{Wei}^{\mathrm{i}^{*}}$ and Shuangcheng $\mathrm{Ma}^{1,2^{*}}$

\begin{abstract}
Background: Diabetes is a complex metabolic disease characterized by hyperglycemia, plaguing the whole world. However, the action mode of multi-component and multi-target for traditional Chinese medicine (TCM) could be a promising treatment of diabetes mellitus. According to the previous research, the TCM of Polygonum multiflorum (PM) showed noteworthy hypoglycemic effect. Up to now, its hypoglycemic active ingredients and mechanism of action are not yet clear. In this study, network pharmacology was employed to elucidate the potential bioactive compounds and hypoglycemic mechanism of PM.

Methods: First, the compounds with good pharmacokinetic properties were screened from the self-established library of PM, and the targets of these compounds were predicted and collected through database. Relevant targets of diabetes were summarized by searching database. The intersection targets of compound-targets and disease-targets were obtained soon. Secondly, the interaction net between the compounds and the filtered targets was established. These key targets were enriched and analyzed by protein-protein interactions (PPI) analysis, molecular docking verification. Thirdly, the key genes were used to find the biologic pathway and explain the therapeutic mechanism by genome ontology $(\mathrm{GO})$ and kyoto encyclopedia of genes and genomes (KEGG) analysis. Lastly, the part of potential bioactive compounds were under enzyme activity inhibition tests.

Results: In this study, 29 hypoglycemic components and 63 hypoglycemic targets of PM were filtrated based on online network database. Then the component-target interaction network was constructed and five key components resveratrol, apigenin, kaempferol, quercetin and luteolin were further obtained. Sequential studies turned out, AKT1, EGFR, ESR1, PTGS2, MMP9, MAPK14, and KDR were the common key targets. Docking studies indicated that the bioactive compounds could stably bind the pockets of target proteins. There were 38 metabolic pathways, including regulation of lipolysis in adipocytes, prolactin signaling pathway, TNF signaling pathway, VEGF signaling pathway, FoxO signaling pathway, estrogen signaling pathway, linoleic acid metabolism, Rap1 signaling pathway, arachidonic
\end{abstract}

\footnotetext{
*Correspondence: weifeng@nifdc.org.cn; masc@nifdc.org.cn

†Yunfei Song, Jianbo Yang contributed equally to this work

${ }^{1}$ School of Chinese Materia Medica, Beijing University of Chinese

Medicine, Beijing 102488, China

${ }^{2}$ Institute for Control of Chinese Traditional Medicine and Ethnic

Medicine, National Institutes for Food and Drug Control, Beijing 100050,

China

Full list of author information is available at the end of the article
}

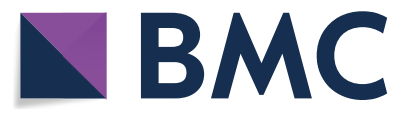

(c) The Author(s) 2020. This article is licensed under a Creative Commons Attribution 4.0 International License, which permits use, sharing, adaptation, distribution and reproduction in any medium or format, as long as you give appropriate credit to the original author(s) and the source, provide a link to the Creative Commons licence, and indicate if changes were made. The images or other third party material in this article are included in the article's Creative Commons licence, unless indicated otherwise in a credit line to the material. If material is not included in the article's Creative Commons licence and your intended use is not permitted by statutory regulation or exceeds the permitted use, you will need to obtain permission directly from the copyright holder. To view a copy of this licence, visit http://creativeco mmons.org/licenses/by/4.0/. The Creative Commons Public Domain Dedication waiver (http://creativecommons.org/publicdomain/ zero/1.0/) applies to the data made available in this article, unless otherwise stated in a credit line to the data. 
acid metabolism, and osteoclast differentiation closely connected with the hypoglycemic mechanism of PM. And the enzyme activity inhibition tests showed the bioactive ingredients have great hypoglycemic activity.

Conclusion: In summary, the study used systems pharmacology to elucidate the main hypoglycemic components and mechanism of PM. The work provided a scientific basis for the further hypoglycemic effect research of PM and its monomer components, but also provided a reference for the secondary development of PM.

Keyword: Polygonum multiflorum, Diabetes, Systematic pharmacology, Bioactive compounds, Hypoglycemic mechanism

\section{Background}

Diabetes, a common chronic metabolic disease of endocrine system, is characterized by hyperglycemia. It is generally believed that diabetes is caused by a lack of insulin secretion activity or insulin resistance. Usually diabetes can be simply divided into type 1 diabetes mellitus (T1DM) and type 2 diabetes mellitus (T2DM) due to different pathogenesis. As a result of the long-term existence of hyperglycemia, it often accompanied by a variety of diabetic complications [1], such as diabetes cardiomyopathy [2], diabetic ketoacidosis [3], diabetic gastroparesis [4], retinopathy [5], diabetic nephropathies [6]. These diabetes-related diseases not only have a huge impact on the body and spirit of the patients, but also bring great pressure to society. Recently, the international diabetes federation (IDF) announced that the number of people with diabetes is on the rise with an average global growth rate of $51 \%$ around the world. Currently, there are 463 million people with diabetes, and there will be 700 million diabetic patients in the whole world by the year of 2045 (https://www.diabetesatlas.org/en/resou rces/). Diabetes mellitus has become the third most serious chronic non-communicable disease after cancer, cardiovascular and cerebrovascular diseases, and has become a serious public health problem which has been put into much attention [7].

Up to now, a great deal of effort and much money have been devoted to developing drugs to treat diabetes, and many drugs have been successfully developed for different targets. Some drugs targeting glucosidase [8], glucagon-like peptide-1 (glp-1) receptor [9], dipeptidase IV (dpp-4) [10], and sodium glucose co-transporter 2(SGLT2) [11] and the like have been already available on market [12]. And some other related to G protein-coupled receptor 119 (GPR119), protein tyrosine phosphatase-1b (PTP1B), glucagon receptor (GCGr), G protein-coupled receptor 40 (GPR40), glycogen synthase kinase 3 (gsk-3), glycogen phosphorylase (GP), and 11-hydroxysteroid dehydrogenase 1 (11-hsd1) are being developed. However, drugs designed for a single target sometimes couldn't contribute to great therapeutic effect because of the complex physical reactions that diabetes brings. Traditional Chinese medicine (TCM) is considered as a complex system due to its intricate components, which correspond to complex organic targets. The system network based on the interaction between multiple components and multiple targets will help to illuminate the complicated mechanism of TCM in the treatment of diseases.

Polygonum multiflorum Thunb. (PM), a classical herbal medicine, has been used for several centuries for its functions of hair-promoted, liver-tonifying and anti-aging $[13,14]$. Previous reports have shown that extracts of PM and its compounds had hypoglycemic effects [15-17]. However, researches on the hypoglycemic properties of PM are still limited and scarce. Therefore, the objective of this study is to elucidate the bioactive ingredients of PM correlated to the hypoglycemic effect and the mechanism of PM on the targets of diabetes. It is of great significance to the secondary development of PM and the further discovery of small molecule antidiabetes ligands.

Network pharmacology [18], an emerged discipline based on systems biology, has been recognized as a promising method to achieve an integral view of complex systems interacting with multiple targets of diseases. This approach coincides with the theory that TCM emphasizes the diagnosis and treatment of diseases from a comprehensive perspective and the synergy among its active compounds of TCM. Consequently, systematic pharmacology has been used to identify the key active constituents, screen the main effective integrates of TCM, investigate the disease-related key targets and biological functions and predict the potential synergetic mechanisms against complicated diseases $[19,20]$.

In the paper, systematic pharmacology was employed to discover the main constituents of PM against diabetes, to screen the core targets terms and to illuminate the crucial corresponding pathway mechanism. First, the compounds with good pharmacokinetic properties were screened from the self-established library of PM, and the targets of these compounds were predicted and collected through the database. Relevant targets of diabetes and related diseases were summarized by searching databases. The intersection targets of compound-targets and disease-targets were obtained soon. Secondly, the interaction net between the compounds and the filtered 
targets was established. These key targets were enriched and analyzed by PPI analysis, molecular docking verification and GO analysis. Finally, the key genes were used to find the biologic pathway and explain the therapeutic mechanism by KEGG analysis. The workflow was summarized in Fig. 1.

\section{Materials and methods}

\section{Construction of PM compounds database}

The ingredients of PM were gathered together from TCMID (https://www.megabionet.org/tcmid/), BATMAN-TCM platform and literature analysis related to PM [21]. Then all the chemical molecular structures and the Smiles numbers were verified and obtained by the platforms such as Pubchem (https://pubchem.ncbi.nlm. nih.gov/), Chembank (https://chembank.broadinstitute. org/), or Scifinder (https://scifinder.cas.org/) [22, 23].

\section{Screening of active ingredients of PM}

In order to select the compounds which have better pharmacokinetic properties and oral bioavailability in vivo, the compounds were filtrated by the principle of "druglike soft" in FAFDrugs4 (https://fafdrugs4.rpbs.univ-paris -diderot.fr/). the active ingredients were picked out when the evaluation results were "accepted". The rule of "druglike soft" contains the restriction to molecular weight, $\log$ P, Hydrogen Bond Acceptors (HBA), Hydrogen Bond Donnors (HBD), topological Polar Surface Area (tPSA), Number of Rotatable Bonds, rigidBonds, het/carbon

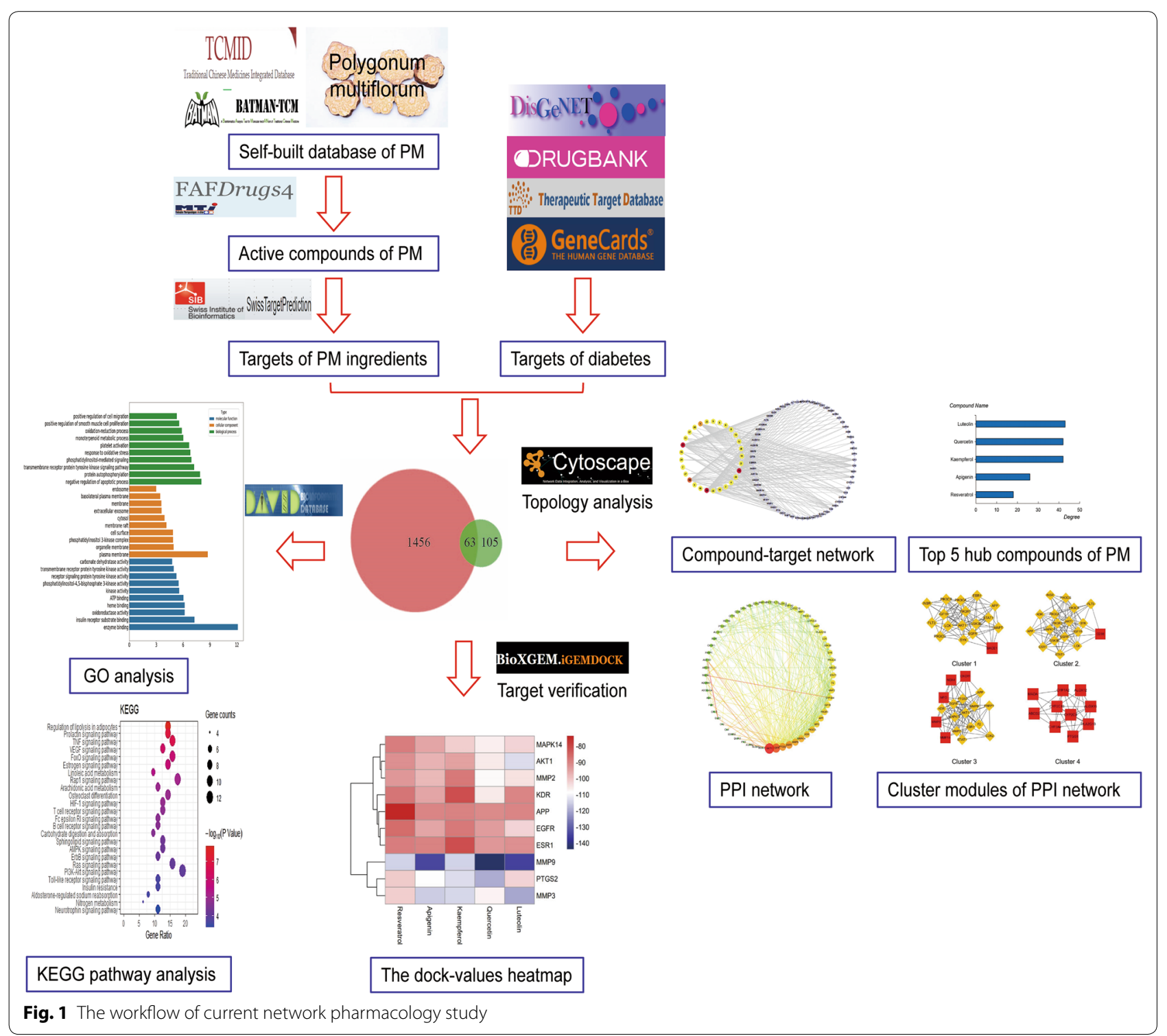


Table 1 The parameters of "Drug-Like Soft" rule

\begin{tabular}{llll}
\hline Property & Range & Property & Range \\
\hline MW & $100-600$ & Rings & $\leq 6$ \\
$\log P$ & -3 to 6 & Max size system ring & $\leq 18$ \\
HBA & $\leq 12$ & Carbons & $3-35$ \\
HBD & $\leq 7$ & Hetero atoms & $1-15$ \\
tPSA & $\leq 180$ & H/C ratio & $0.1-1$ \\
Rotatable bonds & $\leq 11$ & Charges & $\leq 4$ \\
Rigid bonds & $\leq 30$ & Total charge & -4 to 4 \\
\hline
\end{tabular}

atoms ratio ( $\mathrm{H} / \mathrm{C}$ ratio) of compounds properties and the like. The parameters range of rules were specifically in Table 1.

\section{Prediction of compounds targets}

The targets of filtrated compounds were predicted by using the SWISS TARGET PREDICTION (STP) [24] database and SIMILARITY ENSEMBLE APPROACH (SEA) library [25]. Setting the organism " homo sapiens", targets with a probability value greater than 0.25 were considered as potential effective targets for these components in STP database. SEA library was used as a reference.

\section{Diabetes-related targets collection}

The diabetes-related targets were searched in the Therapeutic Target Database (TTD) [26], Drugbank (https ://www.drugbank.ca/), Disgenet (https://www.disgenet. org/) and Genecards platform (https://www.genecards. org/) with "diabetes", "diabetes mellitus" etl. as the keywords [27]. Then these collected targets were merged and removed duplication.

\section{Compound-target network construction}

In order to clarify the hypoglycemic targets of PM, the intersection of compound action targets and diabetes disease targets were taken as the key hypoglycemic targets of PM. Cytoscape 3.2.1 was used to establish the network diagram between the effective compounds of PM and the key diabetes targets. And the network topological properties were analyzed and the results were visualized. In the topological analysis, the degree of nodes and the betweenness centrality were significant indexes to judge the importance of nodes. The larger the degree of nodes, the more biological functions they participated in, and the more vital it was in the network. The betweenness centrality of nodes in the network reflected the closeness of the relationship between nodes. The larger the betweenness centrality, the more important the node was in the network. According to topological analysis, the key active components and main disease targets were screened.

\section{Protein-protein interaction analysis}

The intersection targets were input into the String database to obtain the interaction results among the targets [28], and the visual analysis results were obtained by Cytoscape 3.2.1. Cytoscape-hubba was used to screen hub targets and Cytoscape-clusterONE was used for cluster analysis.

\section{Molecular docking verification}

To verify the effectiveness of the compounds screened, molecular docking simulation was carried out between the key active compounds and the target proteins. The corresponding proteins of top 10 hub target genes were obtained in Protein Data Bank (PDB). Then the PDB format of protein was stored after removing solvent and organic in Pymol soft. Finally the key active compounds and target proteins were docked in the iGEMdock software $[29,30]$. The binding degree of the receptor-ligand can be judged by the level of energy in molecular docking results. Generally, when the binding conformation of the compound and the receptor was stable, the lower the energy was, the greater the possibility of receptorligand interacted.

\section{Gene Ontology and KEGG pathway enrichment analysis}

David database (https://David.Ncifcrf.Gov/summa ry.JSP) is an online tool for gene annotation, classification, enrichment and pathway analysis. Eventually, the key targets annotation and enriched pathways were examined by GO and KEGG pathway enrichment analysis in David database [31, 32]. $\mathrm{p}<0.05$ was used as the threshold to screen the potential signaling pathway and mechanism of hypoglycemic action of PM.

\section{Experimental verification}

In order to verify the hypoglycemic activity of the filtered compounds, the alpha-glucosidase binding in the most common intracellular glucose metabolism during hypoglycemic biological process was selected as the index. The inhibition of alpha-glucosidase activity by the compounds was to be tested.

\section{Results}

Active compound and related targets

There were 187 compounds summarized forming the self-built database of PM through website database and document search. The database mainly includes 
stilbenes, quinones, flavonoids, phospholipids, phenylpropanoids and others. The compounds of PM are listed in the Additional file 1: Table S1. After "drug like soft" in FAFDrugs 4, 95 compounds were screened. Then 37 compounds and their predicted targets were obtained sequentially under the condition of probability value $>0.25$ in STP database. In addition, a total of 1519 diabetes-related targets were acquired through the screening of disease target database. After the intersection of 37 compound-related targets and diabetesrelated targets, 63 hypoglycemic targets and 29 related compounds were obtained. The 29 compounds were shown in detail in Table 2 . The 63 targets were supplied in Additional file 2: Table S2.

\section{The network of compound-targets}

The topological analysis and network diagram of compound-targets were made by using Cytoscape 3.2.1. The degree values of compounds-targets were calculated. The higher the degree is, the closer the relationship between compounds and targets are, and the more important the compounds are in this network. As Fig. 2a shown, the ellipse node represents compound node and the diamond node represents the diabetes disease target. The color of node changed from yellow to red corresponds to degree from small to bigger. The numerical number represents the compound, as shown in Table 1. The target labels are indicated by the target symbols. According to the degree of the compounds, the compounds from 2 times of the average degree (17.24) to the maximum degree (43) were

Table 2 Diabetes-related key compounds in PM

\begin{tabular}{|c|c|c|c|}
\hline No & Compound name & No & Compound name \\
\hline 1 & Resveratrol & 16 & (-)-Epicatechin gallate \\
\hline 2 & Oxyresveratrol & 17 & Tricin \\
\hline 3 & Emodin & 18 & Apigenin \\
\hline 4 & Aloe-emodin & 19 & Kaempferol \\
\hline 5 & Rhein & 20 & Quercetin \\
\hline 6 & Citreorosein & 21 & Luteolin \\
\hline 7 & Teloschistin & 22 & Uridine \\
\hline 8 & Emodin 8-O- $\beta$-D-glucopyranoside & 23 & Adenosine \\
\hline 9 & Physcion 8-O-glucoside & 24 & $\begin{array}{l}\text { 7-Hydroxy-4- } \\
\text { methylcoumarin-5-O- } \beta \text { - } \\
\text { D-glucopyranoside }\end{array}$ \\
\hline 10 & Emodin 1-O- $\beta$-D-glucopyranoside & 25 & $\begin{array}{l}\text { 7-Hydroxy-3,4- } \\
\text { dimethylcoumarin-5-O- } \\
\beta \text {-D-glucopyranoside }\end{array}$ \\
\hline 11 & $(-)$-Catechin & 26 & $(+)$-Catechin 3-O-gallate \\
\hline 12 & (-)-Epicatechin & 27 & 2,6-Dihydroxybenzoic acid \\
\hline 13 & (-)-Gallocatechin & 28 & 3,4-Dihydroxybenzoic acid \\
\hline 14 & (-)-Epigallocatechin & 29 & Gallic acid \\
\hline 15 & $(+)$-Catechin gallate & & \\
\hline
\end{tabular}

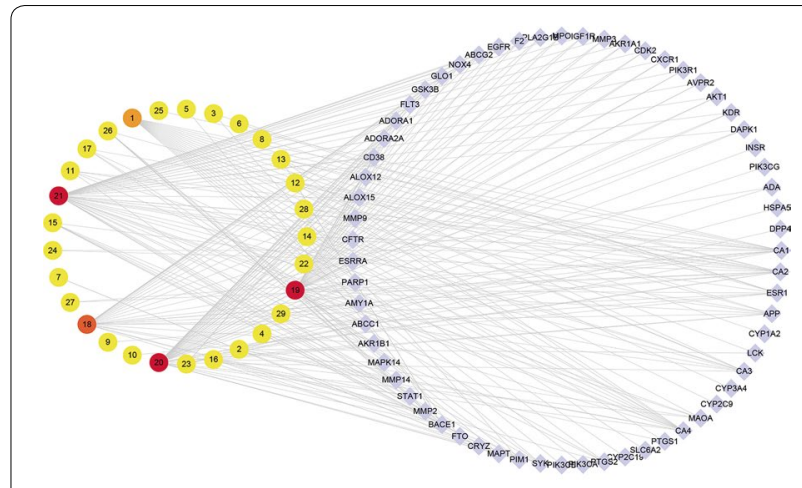

a

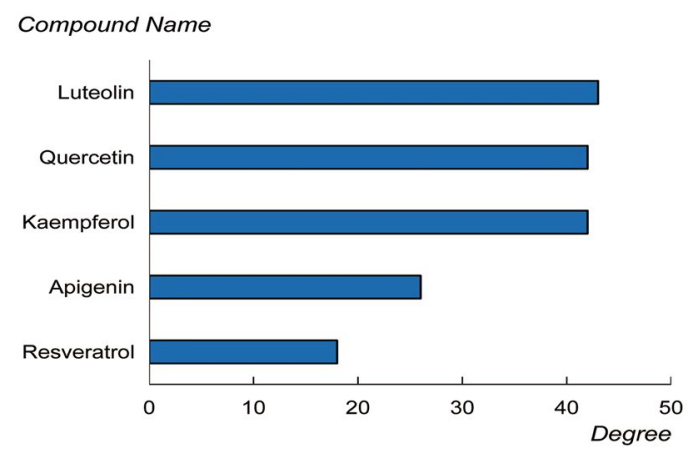

b

Fig. 2 a The network of compound-targets interactions; $\mathbf{b}$ the top five degree compounds of PM

screened out, namely resveratrol, apigenin, kaempferol, quercetin and luteolin, respectively, as shown in Fig. 2b. What was more, ranking the target degrees, 28 targets

Table 3 The information of 28 key targets ranking by degree

\begin{tabular}{llll}
\hline Target symbol & Uniprot ID & Target symbol & Uniprot ID \\
\hline CA2 & P00918 & MAOA & P21397 \\
CA1 & P00915 & ABCG2 & Q9UNQ0 \\
CA4 & P22748 & ALOX12 & P18054 \\
BACE1 & P56817 & ALOX15 & P16050 \\
CA3 & P07451 & CD38 & P28907 \\
ESR1 & P03372 & ESRRA & P11474 \\
APP & P05067 & FLT3 & P36888 \\
MMP2 & P08253 & GLO1 & Q04760 \\
MAPT & P10636 & GSK3B & P49841 \\
SYK & P43405 & MMP9 & P14780 \\
ABCC1 & P33527 & NOX4 & Q9NPH5 \\
ADORA1 & P30542 & PARP1 & P09874 \\
ADORA2A & P29274 & PIM1 & P11309 \\
AKR1B1 & P15121 & PTGS2 & P35354 \\
\hline
\end{tabular}


from the average degree (3.97) to the maximum degree (15) were listed in Table 3.

\section{Protein-protein interaction network}

The interaction relationship between targets was explored based on the String database. The result was shown in Fig. 3a, the target is represented by a circle node. The larger the node is, the higher the degree is and the brighter the color of the node is, the larger the betweenness centrality is. The larger and the brighter

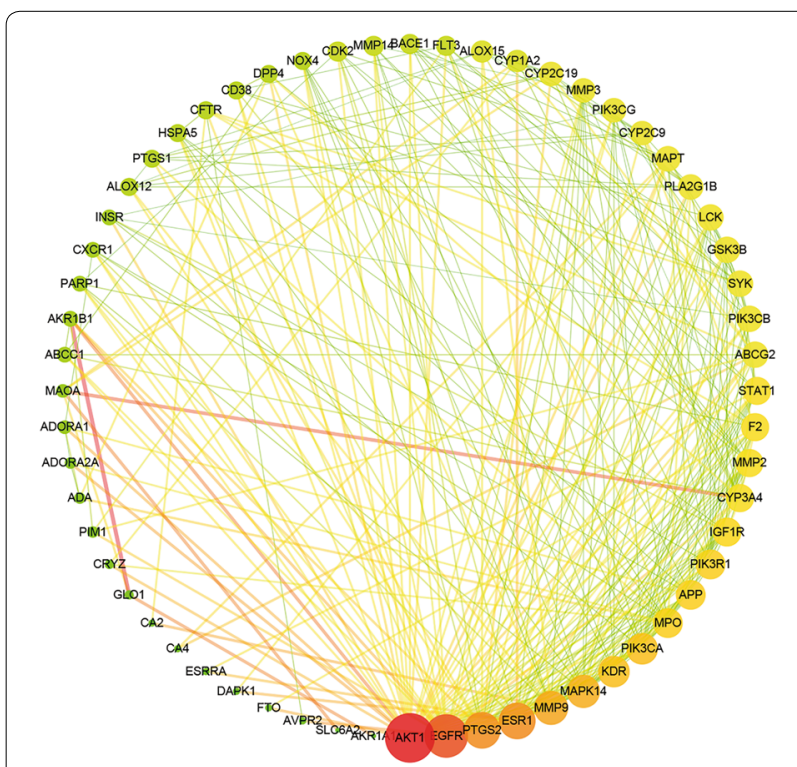

a

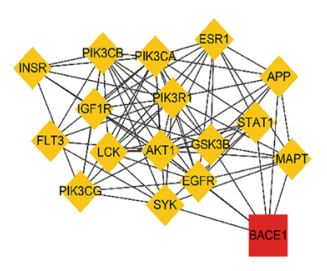

Cluster 1

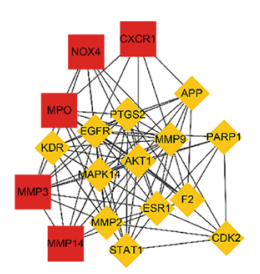

Cluster 3

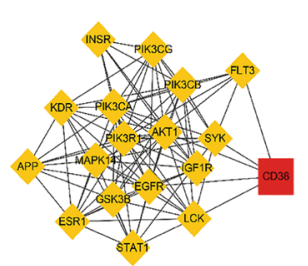

Cluster 2

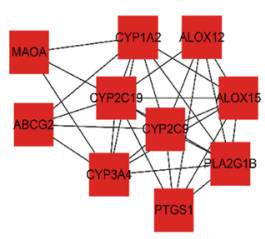

Cluster 4 b

Fig. 3 a The PPI network of key targets; $\mathbf{b}$ the four clustering modules of PPI network color of nodes, the more important the targets are in the hypoglycemia network of PM. The line thickness and the color depth of the nodes represent the size of the edge betweenness value. And the brighter the color of the connection line between the nodes, the thicker the line, indicates the closer the interaction relationship between the targets. At the same time, the module analysis of PPI network was carried out by using Clusterone of Cytoscape 3.2.1. There were four clustering modules with a p-value less than 0.05 among them, indicating that the target proteins in them were more closely related and may jointly perform common biological processes. As Fig. 3b shown, cluster 1 was related to the regulation of intracellular signal transduction, protein kinase B signaling and cell communication. Cluster 2 was linked with protein phosphorylation, phosphate-containing compound metabolic process and regulation of apoptotic process. Cluster 3 was connected with response to oxidative stress, regulation of reactive oxygen species metabolic process. Cluster 4 had a relation to fatty acid derivative metabolic process and oxidation-reduction process. Finally, the hub genes were screened by different algorithms and the results were specially descripted in Table 4 . And it showed that AKT1, EGFR, ESR1, PTGS2, MMP9, MAPK14, and KDR were the common key targets under different algorithms.

\section{Molecular docking results}

The top 5 compounds by the degree ranking and the top 10 targets obtained according to the maximal clique centrality (MCC) algorithm were verified by docking systems. As Fig. 4 showed that all the docking values were all below $-73.75 \mathrm{Kal} / \mathrm{mol}$, all of which showed low docking energy occurred between ligands and receptors. The docking energy was detailed listing in Additional file 3: Table S3. These indicated that the active components of PM could bind to the targets stably and play an effective role in diabetes. Furthermore, based on the average blinding free energy between targets and compounds, the targets ranking from low to high were MMP9, MMP3, PTGS2, AKT1, MAPK14, MMP2, EGFR, KDR, ESR1, APP. And the five compounds with MMP3, MMP9, PTGS2 were all binding with lower docking values. It means that MMP3, MMP9 and PTGS2 may be the important blinding ligands targets related to hypoglycemic effect. And the average docking values between compounds and targets shown that quercetin and luteolin are more lower among the five compounds. It indicates that quercetin and luteolin are more easier to combine with hypoglycemic activity targets.

\section{GO enrichment analysis of key targets}

DAVID website was used for GO enrichment analysis of potential targets, and a total of 208 GO terms with 
Table 4 The top 10 hub genes ranked with different algorithms

\begin{tabular}{|c|c|c|c|c|c|c|}
\hline \multirow[t]{2}{*}{ Category } & \multicolumn{6}{|c|}{ Rank method in CytoHubba } \\
\hline & MCC & MNC & Degree & EPC & Closeness & radiality \\
\hline \multirow[t]{10}{*}{ Gene symbol top 10} & AKT1 & AKT1 & AKT1 & AKT1 & AKT1 & AKT1 \\
\hline & EGFR & EGFR & EGFR & EGFR & EGFR & EGFR \\
\hline & PTGS2 & ESR1 & ESR1 & PTGS2 & PTGS2 & PTGS2 \\
\hline & MAPK14 & PTGS2 & PTGS2 & ESR1 & ESR1 & ESR1 \\
\hline & ESR1 & MMP9 & MMP9 & MAPK14 & MMP9 & MMP9 \\
\hline & KDR & MAPK14 & MAPK14 & MMP9 & MAPK14 & MAPK14 \\
\hline & MMP9 & PIK3CA & PIK3CA & KDR & KDR & KDR \\
\hline & MMP2 & KDR & KDR & PIK3CA & PIK3CA & APP \\
\hline & MMP3 & MPO & MPO & APP & APP & PIK3CA \\
\hline & APP & PIK3R1 & PIK3R1 & IGF1R & IGF1R & IGF1R \\
\hline
\end{tabular}

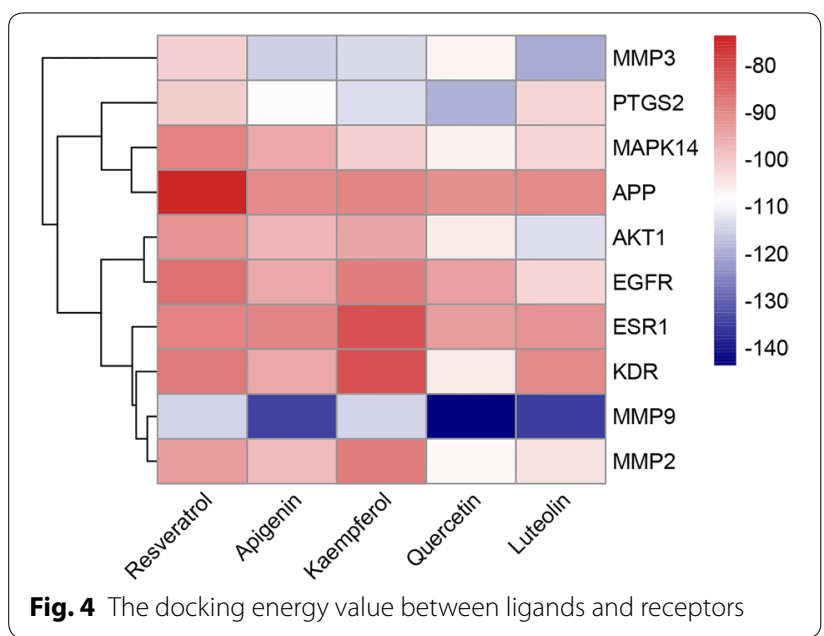

$\mathrm{p}<0.05$ were obtained. Among them, there were 125 entries of biological process (BP), 26 entries of cell composition (CC) and 57 entries of molecular function (MF). Figure 5 listed the top 10 most significantly enriched GO terms respectively. In the biological process category, these targets were mainly concerned with negative regulation of apoptotic process, protein autophosphorylation, transmembrane receptor protein tyrosine kinase signaling pathway, phosphatidylinositol-mediated signaling, response to oxidative stress, monoterpenoid metabolic process, oxidation-reduction process, cellular response to insulin stimulus, inflammatory response. In terms of cell composition, the targets were mainly related to membrane, cytosol, extracellular exosome and endosome. It could be seen from the biological process analysis that the targets mainly involved with enzyme binding, insulin receptor substrate binding, ATP binding, protein serine/ threonine kinase activity and so on.

\section{KEGG enrichment analysis}

The results of KEGG pathway enrichment analysis showed that 63 hypoglycemic targets of PM were significantly enriched in 67 signaling pathways. Through the diabetes database and literature investigation, 38 pathways (Additional file 4: Table S4) were prominently related to the occurrence and development of diabetes. And the main pathways of PM treating diabetes were integrated in Fig. 6. As shown in Fig. 7, a bubble diagram was drawn by listing the top 25 signal pathways according to $\mathrm{p}$ value. Furthermore, the top 10 signaling pathways and their specific related genes information were shown in Table 5. Combined with $\mathrm{p}$ value and false discovery rate (FDR), regulation of lipolysis in adipocytes was the most significant hypoglycemic signaling pathway for PM. Particularly PI3K-Akt signaling pathway contained the most key targets.

\section{Experiment results}

The inhibitory effect of part of screened compounds on alpha-glucosidase activity was detected to evaluate the hypoglycemic activity. Acarbose $(20 \mu \mathrm{g} / \mathrm{ml})$ was selected as the positive control, and the concentration of the compounds to be tested were $10 \mu \mathrm{M}$ to evaluate the inhibition rate on alpha-glucosidase activity. The result was shown in Fig. 8. The alpha-glucosidase inhibition rate of resveratrol, apigenin, luteolin, quercetin, kaempferol, (-)-epicatechin gallate, (-)-catechin, (-)-epicatechin, gallic acid, emodin, rhein and aloe-emodin were $52.6 \%, 31.5 \%$, $32.4 \%, 38.7 \%, 86.2 \%, 62.9 \%, 82.7 \%, 28.6 \%, 27.5 \%, 66 \%$, $16.7 \%, 10.4 \%$ and $12.4 \%$. They all showed great inhibitory activity. Especially for the top 5 compounds, the inhibition rate of resveratrol, apigenin, luteolin, quercetin and kaempferol were all no less than 30\%. The experimental results showed that the screened compounds have good 


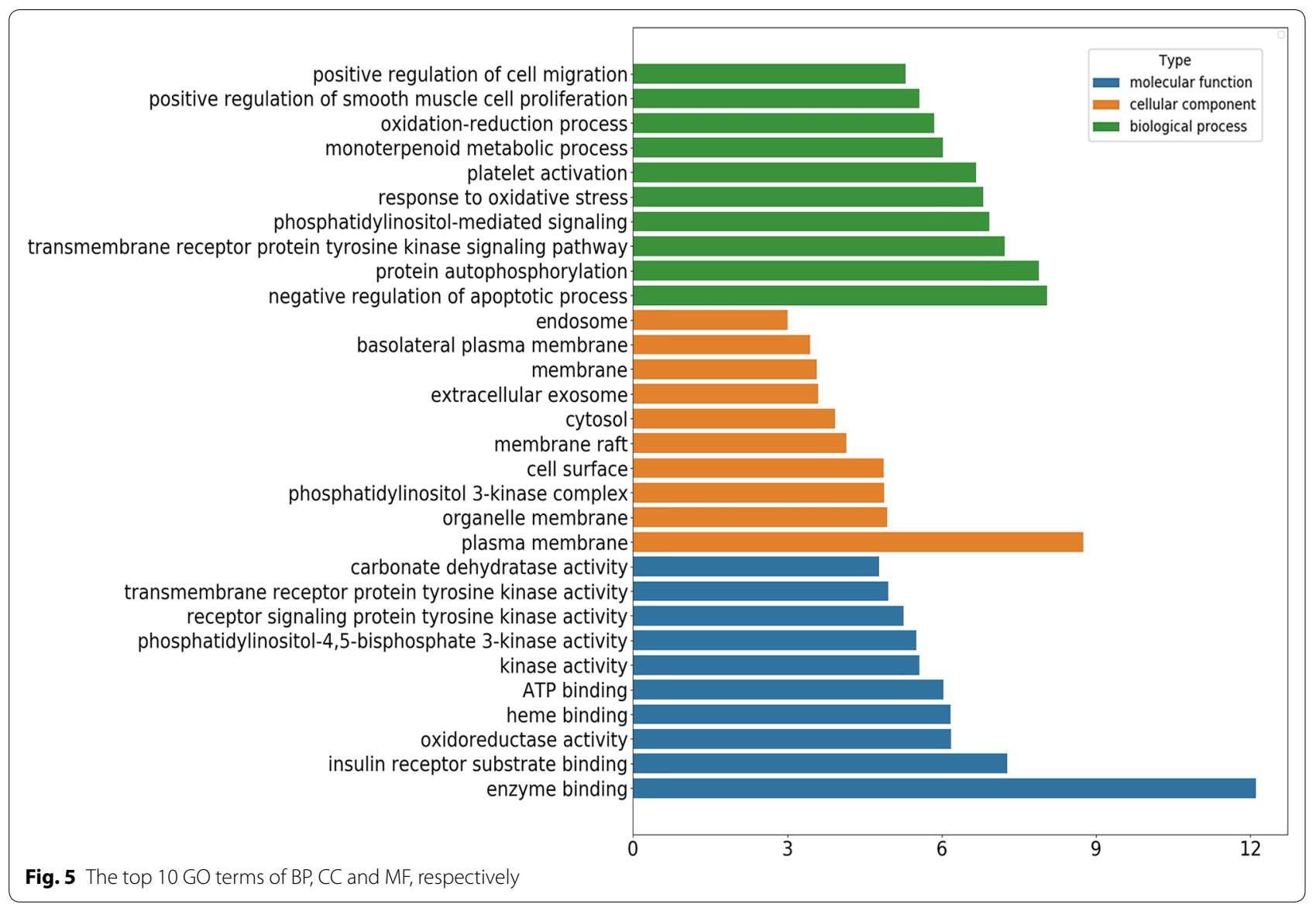

hypoglycemic activity, which could be potential active ingredients.

\section{Discussion}

Based on the evaluation of druggability and network pharmacology screening, 29 components of PM had a potential hypoglycemic effect. Among them, there were 2 stilbene glycosides, 8 quinones, 11 flavonoids, 2 nucleosides, 2 coumarins and 4 others. According to the analysis of sequential compound-target network, the top five compounds contained one stilbene glycoside and four flavonoids, namely resveratrol, apigenin, kaempferol, quercetin and luteolin. Resveratrol (3,5,4'-trihydroxytrans-stilbene), which was reported inhibiting CCR6mediated migration of inflammatory cells, may have a promising treatment with T1DM [33]. Furthermore lots of experiments and clinical trials have shown that resveratrol had beneficial effects on T2DM by improving glucose homeostasis, decreasing insulin resistance, protecting pancreatic beta-cells, improving insulin secretion and ameliorating metabolic disorders [34-37]. Studies also suggested that resveratrol could increase the activity of AMPK and SIRT1, decreasing adipogenic genes and provide some promising mechanisms [38, 39]. Wang commented on the effect of apigenin on streptozotocin (STZ) induced pancreatic $\beta$ cell damage diabetes model. The results showed that apigenin was not only increasing serum insulin and pyruvate kinase, but also regulating to antioxidant defenses of pancreatic cells $[40,41]$. Besides studies suggested that apigenin was sensitive to diabetes by mediating MAPK pathway Regulating ROS/ caspase-3 and NO pathway [42, 43]. Kaempferol, another flavonoid screened, has been proved to have good activity on T2DM and its complications. It was reported that Kaempferol could enhance insulin sensitivity and inhibit hepatic gluconeogenesis to treat with T2DM [44, 45]. In vivo studies have shown that kaempferol down-regulated IKK and suppressed NF-kappa B pathway activation to reduce hepatic inflammatory lesions, which was helpful to insulin signaling defect in diabetes [46]. And Bhatia found kaempferol ameliorated myocardial injury in diabetic rats through suppressing mitogen activated protein kinase (MAPK) pathway and activating AGE-RAGE axis [47]. What is more, in vitro and in vivo evidence have reviewed for quercetin treatment with 


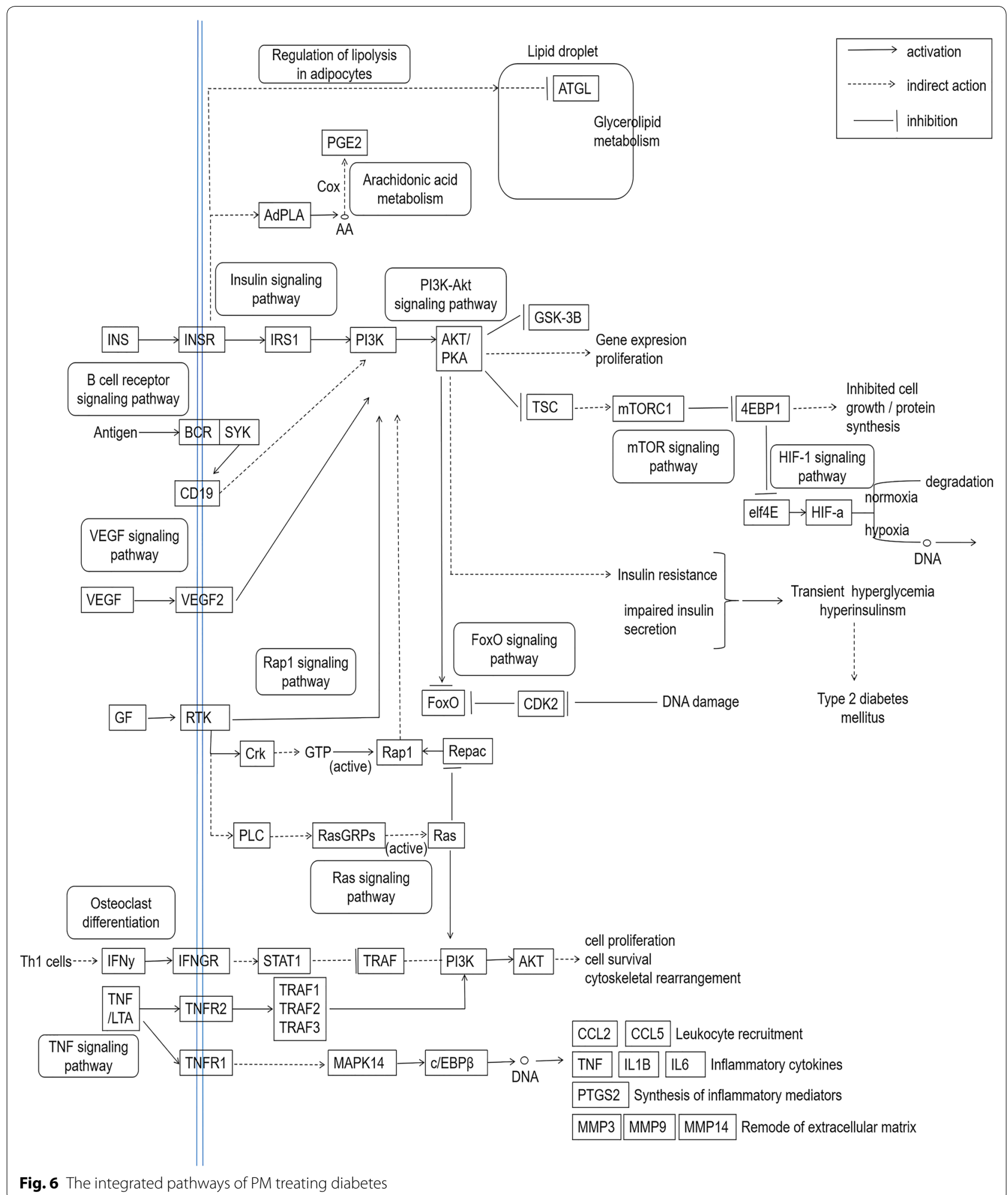

diabetes and its complications $[48,49]$. Research results suggested that quercetin was probably associated with SIRT1/NLRP3 pathway and Akt signaling pathway [50,
51]. Hence, quercetin showed potential for the treatment of glucose and lipid metabolism disorder in diabetes mellitus. Dhanya found that quercetin may correct 


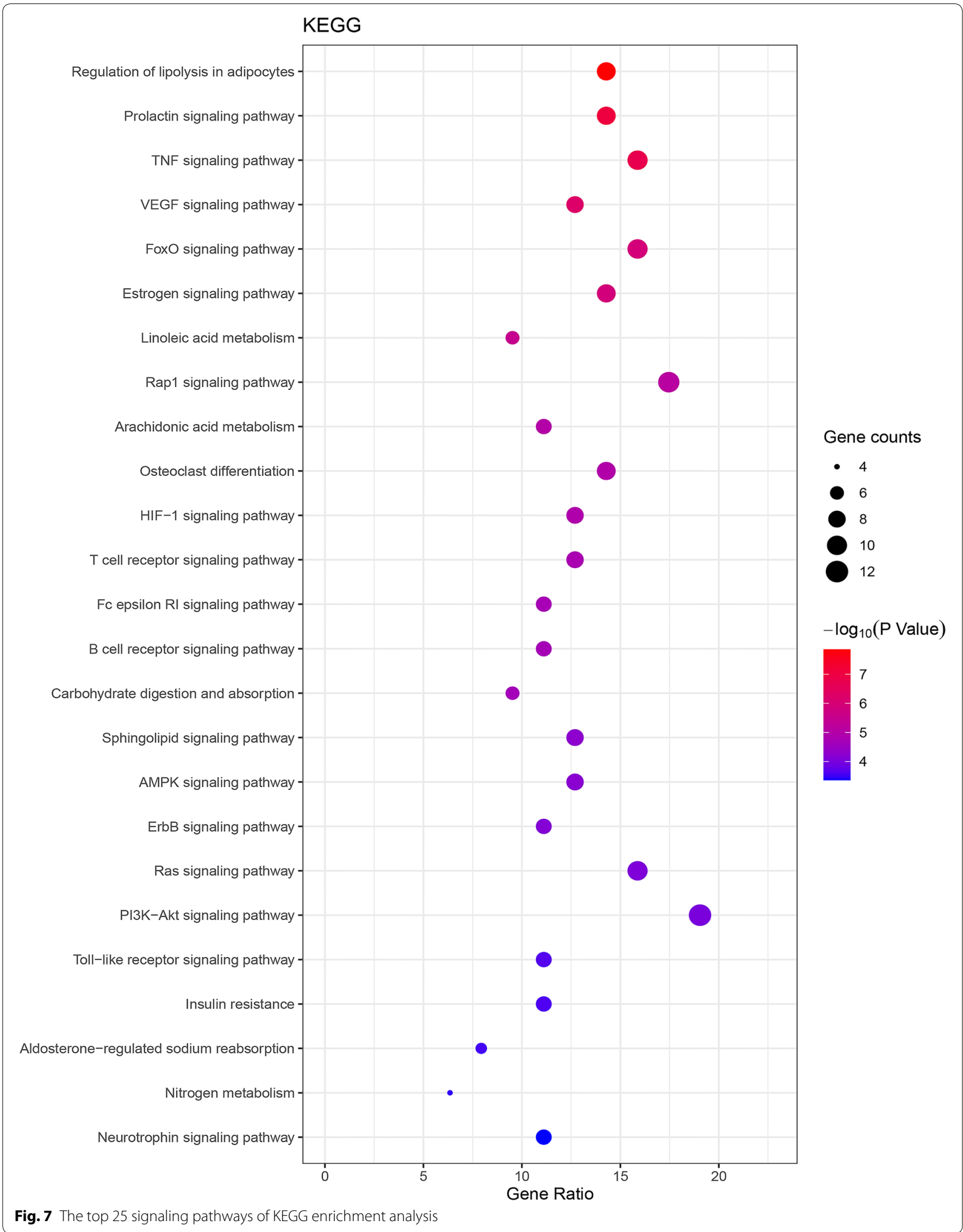


Table 5 The top 10 signaling pathways with related genes

\begin{tabular}{lll}
\hline Term & Pathway & Genes \\
\hline hsa04923 & Regulation of lipolysis in adipocytes & PIK3CG, AKT1, PTGS2, PIK3CB, PTGS1, PIK3CA, ADORA1, INSR, PIK3R1 \\
hsa04917 & Prolactin signaling pathway & PIK3CG, AKT1, PIK3CB, MAPK14, GSK3B, ESR1, PIK3CA, STAT1, PIK3R1 \\
hsa04668 & TNF signaling pathway & PIK3CG, AKT1, PTGS2, PIK3CB, MAPK14, MMP9, PIK3CA, MMP14, MMP3, PIK3R1 \\
hsa04370 & VEGF signaling pathway & PIK3CG, AKT1, PTGS2, PIK3CB, MAPK14, PIK3CA, PIK3R1, KDR \\
hsa04068 & FoxO signaling pathway & PIK3CG, AKT1, EGFR, IGF1R, PIK3CB, MAPK14, PIK3CA, INSR, PIK3R1, CDK2 \\
hsa04915 & Estrogen signaling pathway & PIK3CG, AKT1, EGFR, PIK3CB, MMP9, ESR1, PIK3CA, MMP2, PIK3R1 \\
hsa00591 & Linoleic acid metabolism & CYP3A4, ALOX15, CYP2C19, CYP2C9, PLA2G1B, CYP1A2 \\
hsa04015 & Rap1 signaling pathway & PIK3CG, AKT1, EGFR, IGF1R, ADORA2A, PIK3CB, MAPK14, PIK3CA, INSR, PIK3R1, KDR \\
hsa00590 & Arachidonic acid metabolism & ALOX15, CYP2C19, PTGS2, CYP2C9, PTGS1, PLA2G1B, ALOX12 \\
hsa04380 & Osteoclast differentiation & PIK3CG, AKT1, PIK3CB, MAPK14, LCK, PIK3CA, STAT1, PIK3R1, SYK \\
\hline
\end{tabular}

the insulin resistance through the regulated system for GLUT4 translocation, which was connected with adenosine monophosphate kinase (AMPK) pathway and its downstream target p38 MAPK [52]. Another study showed that ERK1/2 played a major role in quercetin for preventing beta-cell dysfunction [53]. Study also showed luteolin could improve the cardiac function in diabetic rats due to reducing mitochondrial oxidative stress and mitochondrial swelling [54, 55]. Another research suggested that luteolin could ameliorate the cognitive dysfunctions in STZ-induced diabetic rat model by downexpression of glycation end products (AGEs), inhibition of IL-1 and TNF- and upregulating the expressions of GAP-43 and SYN [56]. In addition, Xu caught sight of mast cells playing a key role in diet-induced obesity and diabetes for reducing mast cell and macrophage

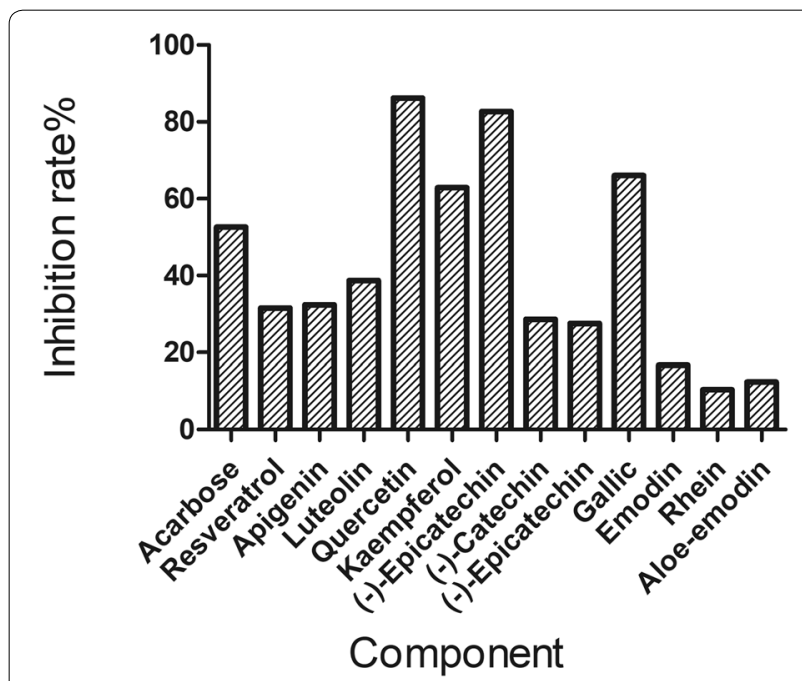

Fig. 8 The alpha-glucosidase inhibition rate of part of potential active ingredients infiltrations and inflammatory cytokine levels and inhibiting mast cell-derived IL-6 expression [57].

Resveratrol have been wildly used for its various of beneficial properties. The rapid elimination and highly effective absorption of resveratrol have been a big issue of bioavailability [58]. Pharmacokinetics studies of resveratrol have been well established in animals and in humans. Measurement of the urinary excretion data indicated a $70 \%$ absorption rate after oral consumption of resveratrol. The half-life times of plasma were $9.2 \mathrm{~h}$ after oral administration and $11.4 \mathrm{~h}$ after intravenous injection in humans [59]. When lower dose (5-50 mg) was given, resveratrol glucuronides are the prominent metabolites in plasma. When higher dose (>250 mg) was given, monosulfates are the main metabolites. It shows a concentrationdependent biotransformation [60]. In addition, blood kinetics showed a high elimination half-time $(91.8 \mathrm{~h})$, a distribution volume of $259 \mathrm{ml}$, and a plasmatic clearance of $1.95 \mathrm{ml} / \mathrm{h}$ for apigenin in the rat. All the pharmacokinetic parameters showed a slow metabolism of apigenin, with a slow absorption and a slow elimination phase. Thus, a possible accumulation of apigenin may occur in the body [61]. kaempferol followed a one-compartment model, with a rapid clearance (4.40-6.44 1/h/ kg) and an extremely short half-life of 2.93-3.79 min after intravenous administration. After oral gavage it was not possible to obtain full plasma concentration-time profiles of kaempferol. Plasma exposure of kaempferol is limited by poor oral bioavailability and extensive metabolism [62]. After absorption, kaempferol is extensively metabolized in the liver to form glucurono- and sulfo-conjugated forms [63]. Some studies have found that kaempferol was metabolized to quercetin and that this effect was probably mediated by the enzymes CYP1A. some of the effects induced by kaempferol in vivo might be mediated in part by quercetin, which is known to have a wide range of biological activities [64]. Quercetin is a natural flavonoid, 
quercetin $(\mathrm{Qr})$, isoquercitrin (IQ), and quercetin-3-O- $\beta$ $\mathrm{D}$-glucuronide $(\mathrm{QG})$ were also mutual transform in vivo. The $t 1 / 2$ of quercetin is about $437 \mathrm{~min}$ [65]. And studies have shown that QG is a major active component in plasma and tissue for oral administration of Qr or QG [66]. Luteolin have the same poor oral bioavailability at $26 \pm 6 \%$ [67]. There are multiple peaks at a Tmax of $0.5 \mathrm{~h}$ and at $4 \mathrm{~h}$ after oral administration of luteolin $(100 \mathrm{mg} /$ $\mathrm{kg}, \mathrm{po}$ ), which suggested that enterohepatic circulation is a general phenomenon [68]. In summary, the five compounds showed significant pharmacokinetic differences. Furthermore they showed slower metabolism, low bioavailability and extensive metabolic transformation, which reflects the synergistic effect of hypoglycemic effects from other side.

The ingredient-target network showed the characteristics of multi-component and multi-target of hypoglycemic in PM. The PPI network illustrated that there was a correlation among the target proteins of PM. The further analysis of PPI results indicated that the hub genes AKT1, EGFR, ESR1, PTGS2, MMP9, MAPK14, and KDR were the common targets of the top 10 in different algorithms. These targets may be the main targets of PM to diabetes mellitus. AKT was responsible for the regulation of glucose uptake by mediating insulin-induced translocation of the SLC2A4/GLUT4 glucose transporter to the cell surface. AKT also regulated the storage of glucose in the form of glycogen and mediated insulin-stimulated protein synthesis (PubMed: 12150915). EGFR was associated with activating several signaling cascades to convert extracellular cues into appropriate cellular responses (PubMed: 2790960). Research suggested that the association between T2DM and ESR1 variants may be because of other unidentified ESR1 polymorphisms that regulated glucose homeostasis [69]. PTGS2, which negatively modulated glucose-stimulated insulin secretion, and functioned as a mediator of the inflammatory response, associated with decreased insulin sensitivity, may play a role in mediating susceptibility to T2DM [70]. Study also suggested that MMP9 might connect with autophagy mediated contractile dysfunction in diabetes [71, 72]. MAPK14 and other proteins, which played crucial roles in the regulation of glucose metabolism, were all significantly down-regulated in the skeletal muscle of diabetic rats and insulin-resistant L6 cells [73]. Khazaei's results demonstrated that reduced serum nitric oxide and vascular endothelial growth factor receptor 2 levels may be responsible for the decreased myocardial capillary density in diabetic rats [74]. In summary, the key targets were of great significance in diabetes and constructed a targetinteraction network for the antidiabetic effect of PM. What's more, it provided a scientific basis for elaborating the mechanism of PM to hypoglycemic effect through multiple targets and multiple pathways.

Diabetes is a complex endocrine system disease involving many metabolic pathways. After KEGG enrichment analysis of key targets, the following top 10 diseaserelated metabolic pathways were obtained. Regulation of lipolysis in adipocytes: lipolysis played a crucial role in obesity-related insulin resistance, and modulating lipolysis in adipocytes may lead to a new treatment to diabetes $[75,76]$. Prolactin signaling pathway: The functions of prolactin receptor has been extended to include islet differentiation, adipocyte control and immune modulation. Also the prolactin signaling pathway disruption has been involved in diabetes [77]. TNF signaling pathway: tumor necrosis factor-alpha (TNF- $\alpha$ ), one of the most crucial pro-inflammatory mediator, induced insulin resistance in adipocytes by impairing the insulin signaling through serine phosphorylation so that leading to the development of T2DM [78]. VEGF signaling pathway: Previous reports indicated that ROS-induced VEGFR2 signaling might be a promising treatment of endothelial dysfunction and serious vascular diseases in diabetes [79]. FoxO signaling pathway: FoxO proteins, which could regulate insulin signaling, gluconeogenesis, insulin resistance, immune cell migration, and cell senescence, have become new clinical entities to treat metabolic disorders and diabetes mellitus [80]. Estrogen signaling pathway: studies have demonstrated that augmenting liver estrogen signaling through ER- $\alpha$ may prevent hepatic insulin resistance and lessen the impact of obesity on diabetes and cardiovascular risk in male rats [81]. Linoleic acid metabolism: reports have shown that the improvements of diabetes could increase the desaturation levels of linoleic acid and its desaturation products in various body compartments [82]. Rap1 signaling pathway: some studies indicated that activated Rap1A promoted glucose-stimulated insulin secretion, islet cell hypertrophy, and islet cell proliferation, and it can be a unique target for the treatment of beta-cell dysfunction in diabetes [83]. Arachidonic acid metabolism: the altered arachidonic acid metabolism and the increased ratio of thromboxane A2 to prostacyclin, which favored an enhanced thrombotic state, may play a role in the accelerated vascular disease of diabetes mellitus [84]. Osteoclast differentiation: it was reported that T2DM could inhibit osteoclastogenesis and osteoclast activity, and delay the degradation of matrix during the alveolar bone regeneration in T2DM rats [85].

In summary, the study clearly illuminated the action mode of multi-component and multi-target of PM in the therapeutical effect on diabetes mellitus. According to KEGG analysis results, PI3K-Akt signaling pathway was the most enriched signaling pathway. And the integrated signaling pathway map showed that the 
PI3K-Akt axis was at the center of all related pathways. This indicated that the PI3K-Akt signaling pathway may be associated with Hypoglycemic effect as the most critical pathway. In addition, a total of 29 components in PM were screened out as the key active components of hypoglycemic, and the most significant 5 key components were verified by molecular docking and enzyme activity inhibition tests. However, there were still some limitations to this study. the result was only based on data mining and network pharmacology analysis. Many unidentified components of PM were still not included in it. In vivo hypoglycemic test verification need further evaluation.

\section{Conclusion}

Based on the mode of action of multi-component and multi-target for traditional Chinese medicine and in line with the principles of network pharmacology, this study systematically explored the bioactive components and mechanism of the hypoglycemic effect of PM. The network interaction diagram of 29 key hypoglycemic components of PM was constructed, corresponding to 63 key hypoglycemic action targets. Furthermore, resveratrol, apigenin, kaempferol, quercetin and luteolin, the five uppermost hypoglycemic components were selected. In addition, the molecular docking method and enzyme activity inhibition tests verified the good activity of the active compounds against diabetic targets. Finally it was found that 38 functional pathways were involved in PM glucose-lowering through data mining and network analysis. As a whole, this study provides reference and scientific basis for further study on the hypoglycemic effect of PM or its active ingredients and the secondary development of PM.

\section{Supplementary information}

Supplementary information accompanies this paper at https://doi. org/10.1186/s13020-020-00401-2.

Additional file 1. The compounds database of PM.

Additional file 2. The hypoglycemic targets related to PM.

Additional file 3. The specific values of docking energy between ligands and receptors.

Additional file 4. The detailed information about 38 related pathways.

\section{Abbreviations}

TCM: Traditional Chinese medicine; PM: Polygonum multiflorum; PPI: Proteinprotein interactions; GO: Genome ontology; KEGG: Kyoto encyclopedia of genes and genomes;T1DM: Type 1 diabetes mellitus;T2DM:Type 2 diabetes mellitus; IDF: International diabetes federation; STP: Swiss target prediction; SEA: Similarity ensemble approach; TTD: Therapeutic target database; PDB: Protein data bank.

\section{Acknowledgements}

Not applicable.

\section{Authors' contributions}

YFS, JBY and SCM proposed the conception; YFS, WGJ, QW, YL and XLC designed and investigated the study analysis; FY and JYT conducted the enzyme activity experiments; YFS, JBY and FW contributed to writing, reviewing and supervising the manuscript; JBY, FW and SCM funded the study. All authors read and approved the final manuscript.

\section{Funding}

This work was financially supported by the National Natural Science Foundation of China (Nos. 81703665, 81773874, 81973476, and 81903807) and National Major Scientific and Technological Special PCnificant New Drugs Development" (2018ZX09735006).

\section{Availability of data and materials}

The datasets used and/or analyzed during the current study are available from the corresponding author upon reasonable request.

Ethics approval and consent to participate Not applicable.

\section{Consent for publication}

Not applicable.

\section{Competing interests}

These authors declare that there are no conflicts of interest regarding this work.

\section{Author details}

${ }^{1}$ School of Chinese Materia Medica, Beijing University of Chinese Medicine, Beijing 102488, China. ${ }^{2}$ Institute for Control of Chinese Traditional Medicine and Ethnic Medicine, National Institutes for Food and Drug Control, Beijing 100050, China. ${ }^{3}$ Institute of Materia Medica, Chinese Academy of Medical Sciences and Peking Union Medical College, Beijing 100050, China.

Received: 23 June 2020 Accepted: 6 November 2020

Published online: 18 November 2020

\section{References}

1. Nishizawa Y. Diabetic complication: definition and classification. Nihon Rinsho. 1991;49(Suppl):3-8.

2. Boudina S, Abel ED. Diabetic cardiomyopathy, causes and effects. Rev Endocr Metab Disord. 2010;11(1):31-9.

3. Farmer AD, Kadirkamanathan SS, Aziz Q. Diabetic gastroparesis: pathophysiology, evaluation and management. Br J Hosp Med. 2012:73(8):451-6.

4. Eledrisi MS, Alshanti MS, Shah MF, Brolosy B, Jaha N. Overview of the diagnosis and management of diabetic ketoacidosis. Am J Med Sci. 2006:331(5):243-51.

5. Wong TY, Cheung CMG, Larsen M, Sharma S, Simó R. Diabetic retinopathy. Nat Rev Dis Primers. 2016;2(1):16012.

6. Boulton AJ, Vinik Al, Arezzo JC, Bril V, Feldman EL, Freeman R, Malik RA, Maser RE, Sosenko JM, Ziegler D. Diabetic neuropathies: a statement by the American Diabetes Association. Diabetes Care. 2005;28(4):956-62.

7. Zhang Y, Bai R, Liu C, Ma C, Chen X, Yang J, Sun D. MicroRNA single-nucleotide polymorphisms and diabetes mellitus: a comprehensive review. Clin Genet. 2019;95(4):451-61.

8. Ghani U. Re-exploring promising a-glucosidase inhibitors for potential development into oral anti-diabetic drugs: finding needle in the haystack. Eur J Med Chem. 2015;103:133-62.

9. George C, Byun A, Howard-Thompson A. New injectable agents for the treatment of type 2 diabetes part 2-glucagon-like peptide-1 (GLP-1) agonists. Am J Med. 2018;131(11):1304-6.

10. Nakamura Y, Hasegawa H, Tsuji M, Udaka Y, Mihara M, Shimizu T, Inoue M, Goto Y, Gotoh H, Inagaki M, et al. Diabetes therapies in hemodialysis patients: Dipeptidase-4 inhibitors. World J Diabetes. 2015;6(6):840-9. 
11. Ho LT, Kulkarni SS, Lee JC. Development of sodium-dependent glucose co-transporter 2 inhibitors as potential anti-diabetic therapeutics. Curr Top Med Chem. 2011;11(12):1476-512.

12. Li W, Yuan G, Pan Y, Wang C, Chen H. Network pharmacology studies on the bioactive compounds and action mechanisms of natural products for the treatment of diabetes mellitus: a review. Front Pharmacol. 2017;8:74.

13. Bounda GA, Feng YU. Review of clinical studies of Polygonum multiflorum Thunb and its isolated bioactive compounds. Pharmacognosy Res. 2015;7(3):225-36.

14. Lin L, Ni B, Lin H, Zhang M, Li X, Yin X, Qu C, Ni J. Traditional usages, botany, phytochemistry, pharmacology and toxicology of Polygonum multiflorum Thunb.: a review. J Ethnopharmacol. 2015;159:158-83.

15. Ham JR, Lee HI, Choi RY, Ryu HS, Yee ST, Kang KY, Lee MK. Heshouwu (Polygonum multiflorum Thunb.) extract attenuates bone loss in diabetic mice. Prev Nutr Food Sci. 2019;24(2):121-7.

16. Venkatakrishnan $\mathrm{K}$, Chiu H-F, Wang C-K. Popular functional foods and herbs for the management of type-2-diabetes mellitus: a comprehensive review with special reference to clinical trials and its proposed mechanism. J Funct Foods. 2019;57:425-38.

17. Yang D, Zhao J, Liu S, Song F, Liu Z. The screening of potential a-glucosidase inhibitors from the Polygonum multiflorum extract using ultrafiltration combined with liquid chromatography-tandem mass spectrometry. Anal Methods. 2014;6(10):3353-9.

18. Hopkins AL. Network pharmacology: the next paradigm in drug discovery. Nat Chem Biol. 2008;4(11):682-90.

19. Zhang R, Zhu X, Bai H, Ning K. Network pharmacology databases for traditional chinese medicine: Review and assessment. Front Pharmacol. 2019;10:123.

20. Li S, Zhang B. Traditional Chinese medicine network pharmacology: theory, methodology and application. Chin J Nat Med. 2013;11(2):110-20.

21. Liu Z, Guo F, Wang Y, Li C, Zhang X, Li H, Diao L, Gu J, Wang W, Li D, et al. BATMAN-TCM: a bioinformatics analysis tool for molecular mechANism of traditional chinese medicine. Sci Rep. 2016;6:21146.

22. Jing C, Sun Z, Xie X, Zhang X, Wu S, Guo K, Bi H. Network pharmacologybased identification of the key mechanism of Qinghuo Rougan Formula acting on uveitis. Biomed Pharmacother. 2019;120:109381.

23. Jiang YB, Zhong M, Long F, Yang RP, Zhang YF, Liu TH. Network pharmacology-based prediction of active ingredients and mechanisms of Lamiophlomis rotata (Benth.) Kudo against rheumatoid arthritis. Front Pharmacol. 2019;10:1435.

24. Daina A, Michielin O, Zoete V. Swiss Target Prediction: updated data and new features for efficient prediction of protein targets of small molecules. Nucleic Acids Res. 2019;47(W1):W357-64.

25. Keiser MJ, Roth BL, Armbruster BN, Ernsberger P, Irwin JJ, Shoichet BK. Relating protein pharmacology by ligand chemistry. Nat Biotechnol. 2007;25(2):197-206

26. Wang Y, Zhang S, Li F, Zhou Y, Zhang Y, Wang Z, Zhang R, Zhu J, Ren Y, Tan $Y$, et al. Therapeutic target database 2020: enriched resource for facilitating research and early development of targeted therapeutics. Nucleic Acids Res. 2020;48(D1):D1031-41.

27. Guo X, Ji J, Feng Z, Hou X, Luo Y, Mei Z. A network pharmacology approach to explore the potential targets underlying the effect of sinomenine on rheumatoid arthritis. Int Immunopharmacol. 2020;80:106201

28. Lin HY, Tsai JC, Wu LY, Peng WH. Reveals of new candidate active components in hemerocallis radix and its anti-depression action of mechanism based on network pharmacology approach. Int J Mol Sci. 2020;21(5):1868.

29. Rosales PF, Marinho FF, Gower A, Chiarello M, Canci B, Roesch-Ely M, Paula FR, Moura S. Bio-guided search of active indole alkaloids from Tabernaemontana catharinensis: Antitumour activity, toxicity in silico and molecular modelling studies. Bioorg Chem. 2019;85:66-74.

30. Hsu KC, Chen YF, Lin SR, Yang JM. iGEMDOCK: a graphical environment of enhancing GEMDOCK using pharmacological interactions and postscreening analysis. BMC Bioinformat. 2011;12(Suppl 1):S33.

31. Song $X Q$, Zhang $Y$, Dai EQ, Wang $L$, Du HT. Prediction of triptolide targets in rheumatoid arthritis using network pharmacology and molecular docking. Int Immunopharmacol. 2020;80:106179.

32. Wang C, Ren Q, Chen X-T, Song Z-Q, Ning Z-C, Gan J-H, Ma X-L, Liang D-R, Guan D-G, Liu Z-L, et al. System pharmacology-based strategy to decode the synergistic mechanism of Zhi-zhu Wan for functional dyspepsia. Front Pharmacol. 2018;9:841.

33. Lee SM, Yang H, Tartar DM, Gao B, Luo X, Ye SQ, Zaghouani H, Fang D. Prevention and treatment of diabetes with resveratrol in a non-obese mouse model of type 1 diabetes. Diabetologia. 2011;54(5):1136-46.

34. Gong L, Guo S, Zou Z. Resveratrol ameliorates metabolic disorders and insulin resistance in high-fat diet-fed mice. Life Sci. 2020;242:117212.

35. Szkudelski T, Szkudelska K. Resveratrol and diabetes: from animal to human studies. Biochim Biophys Acta. 2015;1852(6):1145-54.

36. Jeyaraman MM, Al-Yousif NSH, Singh Mann A, Dolinsky VW, Rabbani R, Zarychanski R, Abou-Setta AM. Resveratrol for adults with type 2 diabetes mellitus. Cochrane Database Syst Rev. 2020;1(1):CD011919.

37. Sadi G, Pektas MB, Koca HB, Tosun M, Koca T. Resveratrol improves hepatic insulin signaling and reduces the inflammatory response in streptozotocin-induced diabetes. Gene. 2015;570(2):213-20.

38. Bagul PK, Banerjee SK. Application of resveratrol in diabetes: rationale, strategies and challenges. Curr Mol Med. 2015;15(4):312-30.

39. Hong B, Ding X, Jia H, Zhang J. Resveratrol ameliorated gestational diabetes through regulation of AMPKmediated NF-kB signaling pathway. Biomed Res. 2017; 28(8).

40. Zhou Y, Wang Z, Xu L, Tang H, Wang D, Meng Q. 39 Studies on the antidiabetic activity of apigenin in mice with streptozotocin-induced diabetes. J Investig Med. 2016;64(Suppl 8):A14.

41. Wang N, Yi WJ, Tan L, Zhang JH, Xu J, Chen Y, Qin M, Yu S, Guan J, Zhang R. Apigenin attenuates streptozotocin-induced pancreatic beta cell damage by its protective effects on cellular antioxidant defense. Vitro Cell Dev Biol Anim. 2017:53(6):554-63.

42. Malik S, Suchal K, Khan SI, Bhatia J, Kishore K, Dinda AK, Arya DS. Apigenin ameliorates streptozotocin-induced diabetic nephropathy in rats via MAPK-NF-kappaB-TNF-alpha and TGF-beta1-MAPK-fibronectin pathways. Am J Physiol Renal Physiol. 2017;313(2):F414-22.

43. Qin W, Ren B, Wang S, Liang S, He B, Shi X, Wang L, Liang J, Wu F. Apigenin and naringenin ameliorate PKCbetall-associated endothelial dysfunction via regulating $\mathrm{ROS} /$ caspase-3 and $\mathrm{NO}$ pathway in endothelial cells exposed to high glucose. Vasc Pharmacol. 2016;85:39-49.

44. Alkhalidy H, Moore W, Wang A, Luo J, McMillan RP, Wang Y, Zhen W, Hulver MW, Liu D. Kaempferol ameliorates hyperglycemia through suppressing hepatic gluconeogenesis and enhancing hepatic insulin sensitivity in diet-induced obese mice. J Nutr Biochem. 2018;58:90-101.

45. Moore W, Alkhalidy H, McMillan R, Zhen W, Wang AH, Liu DM. Small molecule kaempferol prevents type 2 diabetes by promoting insulin sensitivity and reducing hepatic gluconeogenesis. Diabetes. 2014;63:A504-5.

46. Luo C, Yang H, Tang C, Yao G, Kong L, He H, Zhou Y. Kaempferol alleviates insulin resistance via hepatic IKK/NF-kappaB signal in type 2 diabetic rats. Int Immunopharmacol. 2015;28(1):744-50.

47. Bhatia J, Bhatia J, Malik S, Suchal K. A17490 Kaempferol ameliorates myocardial injury in diabetic rats by suppressing oxidative stress, inflammation and apoptosis. J Hypertens. 2018;36:E89.

48. Bule M, Abdurahman A, Nikfar S, Abdollahi M, Amini M. Antidiabetic effect of quercetin: A systematic review and meta-analysis of animal studies. Food Chem Toxicol. 2019;125:494-502.

49. Shi GJ, Li Y, Cao QH, Wu HX, Tang XY, Gao XH, Yu JQ, Chen Z, Yang Y. In vitro and in vivo evidence that quercetin protects against diabetes and its complications: A systematic review of the literature. Biomed Pharmacother. 2019;109:1085-99.

50. Peng J, Li Q, Li K, Zhu L, Lin X, Lin X, Shen Q, Li G, Xie X. Quercetin improves glucose and lipid metabolism of diabetic rats: involvement of akt signaling and SIRT1. J Diabetes Res. 2017;2017:3417306.

51. HuT, Lu XY, Shi JJ, Liu XQ, Chen QB, Wang Q, Chen YB, Zhang SJ. Quercetin protects against diabetic encephalopathy via SIRT1/NLRP3 pathway in db/db mice. J Cell Mol Med. 2020;24(6):3449-59.

52. Dhanya R, Arya AD, Nisha P, Jayamurthy P. Quercetin, a lead compound against type 2 diabetes ameliorates glucose uptake via AMPK pathway in skeletal muscle cell line. Front Pharmacol. 2017;8:336.

53. Youl E, Bardy G, Magous R, Cros G, Sejalon F, Virsolvy A, Richard S, Quignard JF, Gross R, Petit P, et al. Quercetin potentiates insulin secretion and protects INS-1 pancreatic $\beta$-cells against oxidative damage via the ERK1/2 pathway. Br J Pharmacol. 2010;161(4):799-814.

54. Yang JT, Qian LB, Zhang FJ, Wang J, Ai H, Tang LH, Wang HP. Cardioprotective effects of luteolin on ischemia/reperfusion injury in diabetic rats 
are modulated by eNOS and the mitochondrial permeability transition pathway. J Cardiovasc Pharmacol. 2015;65(4):349-56.

55. Su F, Liu SQ, Chen Y, Chen FX, Wang HP, Xia Q. Luteolin reduces cardiac dysfunctions and mitochondrial oxidative stress in streptozotocininduced diabetic rats. FASEB J. 2010;24:49.

56. Gu JX, Cheng XJ, Luo X, Yang X, Pang YY, Zhang XF, Zhang YY, Liu Y. Luteolin ameliorates cognitive impairments by suppressing the expression of inflammatory cytokines and enhancing synapse-associated proteins GAP-43 and SYN levels in streptozotocin-induced diabetic rats. Neurochem Res. 2018;43(10):1905-13.

57. Xu N, Zhang L, Dong J, Zhang X, Chen YG, Bao B, Liu J. Low-dose diet supplement of a natural flavonoid, luteolin, ameliorates diet-induced obesity and insulin resistance in mice. Mol Nutr Food Res. 2014;58(6):1258-68.

58. Breuss JM, Atanasov AG, Uhrin P. Resveratrol and its effects on the vascular system. Int J Mol Sci. 2019;20(7):1523.

59. Wang P, Sang S. Metabolism and pharmacokinetics of resveratrol and pterostilbene. BioFactors. 2018;44(1):16-25.

60. Huang XT, Li X, Xie ML, Huang Z, Huang YX, Wu GX, Peng ZR, Sun YN, Ming QL, Liu YX, et al. Resveratrol: Review on its discovery, anti-leukemia effects and pharmacokinetics. Chem Biol Interact. 2019:306:29-38.

61. Gradolatto A, Basly JP, Berges R, Teyssier C, Chagnon MC, Siess MH, Canivenc-Lavier MC. Pharmacokinetics and metabolism of apigenin in female and male rats after a single oral administration. Drug Metab Dispos. 2005;33(1):49-54.

62. Zabela V, Sampath C, Oufir M, Moradi-Afrapoli F, Butterweck V, Hamburger $\mathrm{M}$. Pharmacokinetics of dietary kaempferol and its metabolite 4-hydroxyphenylacetic acid in rats. Fitoterapia. 2016;1 15:189-97.

63. Barve A, Chen C, Hebbar V, Desiderio J, Saw CL, Kong AN. Metabolism, oral bioavailability and pharmacokinetics of chemopreventive kaempferol in rats. Biopharm Drug Dispos. 2009;30(7):356-65.

64. Calderon-Montano JM, Burgos-Moron E, Perez-Guerrero C, Lopez-Lazaro M. A review on the dietary flavonoid kaempferol. Mini Rev Med Chem. 2011;11(4):298-344.

65. Yin $\mathrm{H}, \mathrm{Ma}$ J, Han J, Li M, Shang J. Pharmacokinetic comparison of quercetin, isoquercitrin, and quercetin-3-O- $\beta$-D-glucuronide in rats by HPLC-MS. PeerJ. 2019;7:e6665.

66. Chen X, Yin OQ, Zuo Z, Chow MS. Pharmacokinetics and modeling of quercetin and metabolites. Pharm Res. 2005;22(6):892-901.

67. Lin LC, Pai YF, Tsai TH. Isolation of Luteolin and Luteolin-7-O-glucoside from dendranthema morifolium ramat tzvel and their pharmacokinetics in rats. J Agric Food Chem. 2015;63(35):7700-6.

68. Shi F, Pan H, Lu Y, Ding L. An HPLC-MS/MS method for the simultaneous determination of luteolin and its major metabolites in rat plasma and its application to a pharmacokinetic study. J Sep Sci. 2018;41(20):3830-9.

69. Dahlman I, Vaxillaire M, Nilsson M, Lecoeur C, Gu HF, Cavalcanti-Proenca C, Efendic S, Ostenson CG, Brismar K, Charpentier G, et al. Estrogen receptor alpha gene variants associate with type 2 diabetes and fasting plasma glucose. Pharmacogenet Genomics. 2008;18(11):967-75.

70. Konheim YL, Wolford JK. Association of a promoter variant in the inducible cyclooxygenase-2 gene (PTGS2) with type 2 diabetes mellitus in Pima Indians. Hum Genet. 2003;113(5):377-81.
71. Mishra PK, Chavali V, Metreveli N, Tyagi SC. Ablation of MMP9 induces survival and differentiation of cardiac stem cells into cardiomyocytes in the heart of diabetics: a role of extracellular matrix. Can J Physiol Pharmacol. 2012a;90(3):353-60.

72. Mishra PK, Chavali V, Metreveli N, Tyagi SC. Targeted deletion of MMP9 mitigates autophagy mediated contractile dysfunction in insulin2 mutant diabetic mice. Circulation. 2012b;126(21):A19387.

73. Zhou T, Meng X, Che H, Shen N, Xiao D, Song X, Liang M, Fu X, Ju J, Li Y, et al. Regulation of Insulin Resistance by Multiple MiRNAs via Targeting the GLUT4 Signalling Pathway. Cell Physiol Biochem. 2016;38(5):2063-78.

74. Khazaei M, Fallahzadeh AR, Sharifi MR, Afsharmoghaddam N, Javanmard SH, Salehi E. Effects of diabetes on myocardial capillary density and serum angiogenesis biomarkers in male rats. Clinics. 2011;66(8):1419-24.

75. Ivanov V, Shakhristova EV, Stepovaya EA, Nosareva OL, Fedorova TS, Ryazantseva NV, Novitsky W. Effect of insulin, the glutathione system, and superoxide anion radical in modulation of lipolysis in adipocytes of rats with experimental diabetes. Biochemistry. 2015;80(1):87-96.

76. Grahn TH, Kaur R, Yin J, Schweiger M, Sharma VM, Lee MJ, Ido Y, Smas CM, Zechner R, Lass A, et al. Fat-specific protein 27 (FSP27) interacts with adipose triglyceride lipase (ATGL) to regulate lipolysis and insulin sensitivity in human adipocytes. J Biol Chem. 2014;289(17):12029-39.

77. Akash MSH, Rehman K, Liaqat A. Tumor Necrosis Factor-Alpha: Role in Development of Insulin Resistance and Pathogenesis of Type 2 Diabetes Mellitus. J Cell Biochem. 2018;119(1):105-10.

78. Moriya J, Ferrara N. Inhibiting the response to VEGF in diabetes. Sci Signal. 2014;7(307):pe1.

79. Maiese K. FoxO transcription factors and regenerative pathways in diabetes mellitus. Curr Neurovasc Res. 2015;12(4):404-13.

80. Gorvin CM. The prolactin receptor: diverse and emerging roles in pathophysiology. J Clin TransI Endocrinol. 2015;2(3):85-91.

81. Zhu L, Martinez MN, Emfinger CH, Palmisano BT, Stafford JM. Estrogen signaling prevents diet-induced hepatic insulin resistance in male mice with obesity. Am J Physiol Endocrinol Metab. 2014;306(10):E1188-97.

82. Vandoormaal JJ. Linoleic-acid metabolism in diabetes-mellitus. Neth J Med. 1990;37(5-6):207-14.

83. Kelly P, Bailey CL, Fueger PT, Newgard CB, Casey PJ, Kimple ME. Rap1 promotes multiple pancreatic islet cell functions and signals through mammalian target of rapamycin complex 1 to enhance proliferation. J Biol Chem. 2010;285(21):15777-85.

84. Halushka PV, Mayfield R, Colwell JA. Insulin and arachidonic acid metabolism in diabetes mellitus. Metabolism. 1985;34(12 Suppl 1):32-6.

85. Hu Z, Ma C, Liang Y, Zou S, Liu X. Osteoclasts in bone regeneration under type 2 diabetes mellitus. Acta Biomater. 2019;84:402-13.

\section{Publisher's Note}

Springer Nature remains neutral with regard to jurisdictional claims in published maps and institutional affiliations.

\footnotetext{
Ready to submit your research? Choose BMC and benefit from:

- fast, convenient online submission

- thorough peer review by experienced researchers in your field

- rapid publication on acceptance

- support for research data, including large and complex data types

- gold Open Access which fosters wider collaboration and increased citations

- maximum visibility for your research: over $100 \mathrm{M}$ website views per year
}

At BMC, research is always in progress.

Learn more biomedcentral.com/submissions 